\title{
Atenção psicossocial e o cuidado em saúde à população em situação de rua: uma revisão integrativa
}

\author{
Psychosocial care and healthcare for the homeless population: \\ an integrative review
}

Lívia Bustamante van Wijk (https://orcid.org/0000-0002-6031-5923) ${ }^{1}$

Elisabete Ferreira Mângia (https://orcid.org/0000-0002-2572-6639) ${ }^{1}$

${ }^{1}$ Faculdade de Medicina, Universidade de São Paulo. Rua Cipotânea 51, Butantã. 05360-160 São Paulo SP Brasil.livia_bustamante@ yahoo.com.br

\begin{abstract}
The homeless population has physical and mental health issues and is exposed to conditions that lead to vulnerabilities, premature mortality, difficulty of access to basic services, all of which demands intersectoral actions. Outreach homeless clinics are components of Primary Health Care of the psychosocial health services network and play an important role in healthcare for this group. The goals of this integrative review are to assess health actions directed to this population, identify if actions result from dialogue between health service providers and the population attended and if such actions are sufficient to cater to their needs. Initially, 264 related papers were located, 27 of which were pre-selected and a further 11 were selected using pre-defined criteria. The findings were divided into 3 categories: 1 ) Characteristics of health actions seeking to cater to the needs of the homeless population; 2) Factors limiting health actions that restrict the care to the needs of this population; 3) Participation of the homeless population in the planning and execution of actions provided by the health services. The studies show advances in access to basic rights and provide input that support initiatives to enhance and strengthen the provision of intersectoral care to this population.

Key words Homeless population, Health, Mental health, Intersectoriality
\end{abstract}

Resumo A população em situação de rua apresenta agravos à saúde física e mental e está exposta a condições que implicam em vulnerabilidades, mortalidade prematura, dificuldade de acesso a serviços e que requerem ações intersetoriais. Os Consultórios na Rua, componentes da Atenção Básica em Saúde da Rede de Atenção Psicossocial, desempenham importante papel no cuidado a esse grupo. Com o objetivo de conhecer as ações de saúde dirigidas a essa população; identificar se elas são construídas a partir do diálogo entre serviços e pessoas atendidas; e se respondem às suas necessidades; foi desenvolvida esta revisão integrativa. Foram encontrados inicialmente 264 estudos: 27 foram pré-selecionados e 11 selecionados. Os achados foram sistematizados em três categorias: 1) Características das ações de saúde que buscam responder às necessidades da população em situação de rua; 2) Fatores que limitam as ações de saúde e restringem a resposta às necessidades dessa população e 3) Participação das pessoas em situação de rua no planejamento e na execução das ações oferecidas pelos serviços de saúde. Os estudos apontam avanços no acesso a direitos básicos e trazem contribuições que apoiam iniciativas de ampliação e fortalecimento da oferta de atenção intersetorial a essa população.

Palavras-chave População em situação de rua, Saúde, Saúde mental, Intersetorialidade 


\section{Introdução}

Nas últimas duas décadas, o cuidado à população em situação de rua vem sendo objeto de responsabilização pública. A Política Nacional para Inclusão Social da População em Situação de Rua ${ }^{1}$ compreende essa população como:

grupo populacional heterogêneo que tem em comum a pobreza, vinculos familiares quebrados ou interrompidos, vivência de um processo de desfiliação social pela ausência de trabalho assalariado e das proteções derivadas ou dependentes dessa forma de trabalho, sem moradia convencional regular e tendo a rua como o espaço de moradia e sustento.

A contingência do viver na rua define a condição de grande vulnerabilidade social desse grupo, caracterizada pela precarização das condições de vida e saúde ${ }^{2,3}$, exposição a fatores de risco e violências ${ }^{2,4,5}$, ausência de acesso a fontes de renda e direitos humanos e sociais ${ }^{6}$ e discriminação em relação ao acesso a bens e serviços de saúde ${ }^{6-8}$.

Pessoas em situação de rua tendem a não se reconhecer como detentoras de direitos ${ }^{4}$ e apresentam agravos à saúde física e mental mais significativos do que a população em geral. A presença de transtornos mentais, associados ou não ao uso prejudicial de substâncias, como álcool, crack e outras drogas, bem como a mortalidade prematura, são fatores que requerem ações intersetoriais, preferivelmente coordenadas pela atenção primária em saúde?.

Em 2008, a Pesquisa Nacional sobre a População em Situação de Rua indicou que 31.922 adultos se encontravam em situação de rua no Brasil, dos quais $82 \%$ eram homens; $67 \%$ se declararam pardos ou negros; $24,8 \%$ não possuíam documento de identificação; $88,5 \%$ afirmaram não receber nenhum benefício do governo e $63,5 \%$ não concluíram o $1^{\circ}$ grau $^{10}$. Já em 2015, outro estudo estimou que 101.854 pessoas se encontravam em situação de rua no país ${ }^{11}$.

De um modo geral, os serviços de saúde limitam o acesso, restringem o acolhimento e não respondem às necessidades dessa população, o que leva ao abandono dos acompanhamentos ${ }^{4}$. Tal situação é agravada quando as pessoas em situação de rua apresentam transtornos mentais e estudos destacam limitações das Políticas Públicas voltadas para esse grupo ${ }^{7,8}$.

Apesar dos limites apontados, o campo da saúde tem buscado alinhamento ao que é preconizado pela Organização Mundial de Saúde (OMS) ${ }^{12}$, que propõe que se priorize o cuidado a grupos vulneráveis articulado ao exercício de direitos humanos e de cidadania. No Brasil, a implementação da Rede de Atenção Psicossocial (RAPS) busca supe- rar a fragmentação das ações e serviços de saúde e ampliar os serviços para o acolhimento das pessoas em vulnerabilidade ${ }^{13}$. Reconhece a necessidade de desenvolver ações dirigidas à população em situação de rua, que considerem suas especificidades e contemplem a oferta de cuidados adequados em saúde mental ${ }^{14,15}$.

Nesse contexto, são propostas as equipes de Consultório na Rua, componentes da Atenção Básica em Saúde da RAPS. Tais equipes estão vinculadas à Política Nacional de Atenção Básica e sua proposição se deu a partir de experiências da Atenção Básica voltadas à população em situação de rua nas cidades de Belo Horizonte, Porto Alegre, São Paulo e Rio de Janeiro, e do trabalho realizado pelas equipes de Consultório de Rua, que eram ligadas à Coordenação Nacional de Saúde Mental ${ }^{16-18}$. Atualmente existem no Brasil 144 equipes, que estão mais concentradas na região sudeste ${ }^{19}$.

Em parceria com outros serviços, essas equipes se responsabilizam pela oferta de cuidados integrais nos locais em que as pessoas em situação de rua se encontram, o que inclui ações em saúde mental a todos e em especial aos que apresentam transtornos mentais e/ou fazem uso de crack, álcool e outras drogas ${ }^{15,16,20}$.

Compreender e refletir sobre o cuidado às pessoas em situação de rua, em especial àquelas que apresentam transtornos mentais, envolve reconhecer a complexidade sócio-política da questão e conhecer as ações desenvolvidas pelos serviços de saúde que são dirigidas a essa população. Na busca de subsídios para essa tarefa, foi desenvolvida uma revisão integrativa da literatura nacional que tomou como objeto de estudo o cuidado à população em situação de rua oferecido por serviços de saúde da RAPS. Seus objetivos foram conhecer as ações dirigidas a essa população; identificar se elas são construídas a partir do diálogo entre serviços e pessoas atendidas e se respondem às suas necessidades.

Norteia o estudo o questionamento sobre como as reais necessidades dessa população ganham visibilidade no planejamento, oferta e resultados das ações, no contexto da atual produção bibliográfica nacional. Busca-se discutir se as ações se encontram articuladas a eixos de cuidados propostos pela RAPS ${ }^{15}$ como garantia de acesso; humanização; estabelecimento de vínculo; escuta qualificada; redução de danos e construção do trabalho em rede.

\section{Métodos}

Esta revisão integrativa foi feita de acordo com seguintes passos propostos pela literatura: 1) 
identificação do tema e seleção da questão de pesquisa; 2) busca pela melhor evidência, a partir do estabelecimento de critérios de inclusão e exclusão; 3) identificação e avaliação crítica dos estudos pré-selecionados e selecionados; 4) categorização dos estudos selecionados e integração das evidências por meio da matriz de síntese; 5) análise, interpretação e discussão dos resultados e 6) apresentação da síntese do conhecimento produzido $^{21,22}$.

As bases de dados utilizadas para a pesquisa foram Lilacs (Literatura Latinoamericana em Ciências da Saúde) e SciELO (Scientific Electronic Library Online) a partir da BVS (Biblioteca Virtual em Saúde). Os descritores utilizados e associados foram "pessoas em situação de rua"; "população em situação de rua"; "moradia"; "saúde"; "saúde mental"; "serviços de saúde mental" e "atenção psicossocial".

Também foram pesquisadas dissertações e teses no Portal de Periódicos da Coordenação de Aperfeiçoamento de Pessoal de Nível Superior (CAPES) - por meio do site www.periodicos. capes.gov.br - a partir dos termos "situação de rua" e "moradores de rua", no contexto do tema "Saúde Pública".

Em relação ao tempo de publicação, foram selecionados estudos publicados há até 10 anos (a partir de 2005). A busca por estudos para a revisão foi realizada no mês de novembro de 2015.

Nas bases de dados, os descritores foram associados da seguinte maneira: "pessoas em situação de rua OR população em situação de rua AND saúde"; "pessoas em situação de rua OR população em situação de rua AND saúde mental AND serviços de saúde mental"; "pessoas em situação de rua OR população em situação de rua AND saúde mental OR serviços de saúde mental"; "pessoas em situação de rua OR população em situação de rua AND saúde mental OR atenção psicossocial"; "pessoas em situação de rua OR população em situação de rua OR moradia AND saúde mental".

Por meio da busca realizada na base de dados Lilacs foram encontrados inicialmente 180 estudos. Após a leitura criteriosa dos títulos e resumos dos artigos, com o intuito de identificar quais se adequavam aos objetivos da revisão, foram selecionados 27 para a leitura completa, sendo 26 artigos e uma tese de doutorado. $\mathrm{Na}$ busca realizada na SciELO foram encontrados 23 artigos, dos quais 4 foram encaminhados para a leitura completa, porém todos eles já se encontravam nos achados da Lilacs.

No Portal de Periódicos da CAPES foram encontrados 64 resultados, entre dissertações e teses. Após leitura dos títulos e resumos, foram selecionadas 3 dissertações de mestrado, mas que foram dispensadas após a leitura completa por não se adequarem aos objetivos da revisão.

Foram selecionados estudos cujo texto completo se encontrava disponível. O critério para inclusão de artigos foi ter como temática principal o estudo, descrição ou problematização de ações desenvolvidas por serviços de saúde e dirigidas à população em situação de rua. Os critérios de exclusão foram: estudos teóricos e/ou genéricos, que enfocam prevalência de diagnósticos ou que abordam questões clínicas específicas, como doenças sexualmente transmissíveis (DST) e tuberculose, além de estudos realizados em outros países, de modo a se manter a discussão referente às Políticas Públicas voltadas à população em situação de rua no Brasil.

\section{Resultados}

A partir da leitura criteriosa dos 27 estudos encontrados foram selecionados 13 artigos (dos quais 4 também se encontravam indexados na SciELO) e uma tese de doutorado (Tabela 1). Foi elaborado um quadro que caracteriza os estudos selecionados (Quadro 1) bem como a matriz de síntese para análise (Quadro 2).

Todos os estudos se encontram indexados na Lilacs e $36,4 \%$ (4) deles também indexados na SciELO. $57,1 \%$ (8) das publicações são provenientes do estado de São Paulo; 14,3\% (2) são do Rio de Janeiro; $14,3 \%$ (2) são de Pernambuco e as outras duas são do Rio Grande do Sul e Goiânia. Em relação aos periódicos nos quais os artigos se encontram publicados, $21,4 \%$ (3) são da Revista da Escola de Enfermagem da Universidade de São Paulo (USP), 14,3\% (2) são dos Cadernos de Saúde Pública e os demais (9) se distribuem entre Saúde em Debate; Psicologia em Estudo; Cadernos de Terapia Ocupacional na Universidade de São Carlos; Interface - Comunicação, Saúde e Educação; Physys - Revista de Saúde Coletiva; Revista Polis e Psique; Saúde e Sociedade; Revista Brasileira de Enfermagem; além da tese de doutorado em Psicologia Social da Pontifícia Universidade Católica (PUC) de São Paulo.

Quanto ao período de publicação, 28,6\% (4) foram publicados em 2014; 21,4\% (3) em 2015; 21,4\% (3) em 2013; 14,3\% (2) em 2007 e há um estudo de 2010 e outro de 2006. Em relação à metodologia, $64,3 \%$ (9) são pesquisas qualitativas; $21,4 \%$ (3) são relatos de experiência e os outros dois se distribuem entre revisão narrativa e estudo quanti-qualitativo. 


\begin{tabular}{|c|c|c|c|c|}
\hline \multicolumn{5}{|l|}{3360} \\
\hline \multirow[t]{6}{*}{ 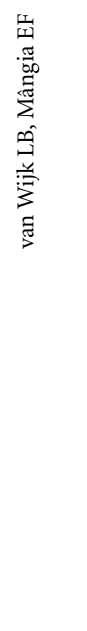 } & \multicolumn{4}{|c|}{$\begin{array}{l}\text { Tabela 1. Distribuição da seleção de publicações } \\
\text { de bases de dados de acordo com os critérios } \\
\text { estabelecidos para a inclusão de estudos - São Paulo, } \\
\text { SP, Brasil, 2017. }\end{array}$} \\
\hline & $\begin{array}{c}\text { Base de } \\
\text { dados }\end{array}$ & Encontrados & $\begin{array}{c}\text { Pré- } \\
\text { selecionados }\end{array}$ & Selecionados \\
\hline & Lilacs & 180 & 27 & 14 \\
\hline & SciELO & 23 & $\begin{array}{c}4 \\
\text { (já inclusos) }\end{array}$ & $\begin{array}{c}4 \\
\text { (já inclusos) }\end{array}$ \\
\hline & $\begin{array}{l}\text { Portal } \\
\text { CAPES }\end{array}$ & 64 & 3 & 0 \\
\hline & Total & 267 & 30 & 14 \\
\hline
\end{tabular}

A leitura criteriosa dos estudos permitiu a sistematização dos achados em três categorias correlacionadas aos objetivos da revisão: 1) Características das ações de saúde que buscam responder às necessidades da população em situação de rua; 2) Fatores que limitam as ações de saúde e restringem a resposta às necessidades da população em situação de rua e 3) Participação das pessoas em situação de rua no planejamento e na execução das ações oferecidas pelos serviços de saúde. Cada uma delas será apresentada a seguir.

Quadro 1. Informações gerais dos estudos selecionados: título; autores; local, periódico e ano de publicação; tipo de estudo - São Paulo, SP, Brasil, 2017.

\begin{tabular}{|c|c|c|c|c|c|}
\hline & Título do estudo & Autores & Local & Revista / Ano & Tipo \\
\hline 1 & $\begin{array}{l}\text { Práticas de cuidado e população em situação } \\
\text { de rua: o caso do Consultório na Rua }{ }^{23}\end{array}$ & Silva CC et al. & RJ & $\begin{array}{l}\text { Saúde Debate / } \\
2015\end{array}$ & Qualitativo \\
\hline 2 & $\begin{array}{l}\text { Consultório na Rua: atenção a pessoas em } \\
\text { uso de substâncias psicoativas }{ }^{24}\end{array}$ & $\begin{array}{l}\text { Lima HS, Seidl } \\
\text { EMF }\end{array}$ & GO & $\begin{array}{l}\text { Psicologia em } \\
\text { estudo / } 2015\end{array}$ & Qualitativo \\
\hline 3 & $\begin{array}{l}\text { Consultório na Rua: visibilidades, } \\
\text { invisibilidades e hipervisibilidade }{ }^{25}\end{array}$ & $\begin{array}{l}\text { Hallais JAS, Barros } \\
\text { NF }\end{array}$ & SP & $\begin{array}{l}\text { Cad Saúde } \\
\text { Pública / } 2015\end{array}$ & Qualitativo \\
\hline 4 & $\begin{array}{l}\text { A experiência no serviço de Consultório } \\
\text { de Rua na perspectiva dos profissionais: } \\
\text { Contribuições para a atenção ao usuário de } \\
\text { álcool e outras drogas }{ }^{26}\end{array}$ & Souza VCA et al. & $\mathrm{PE}$ & $\begin{array}{l}\text { Cad Ter Ocup } \\
\text { UFSCar / } 2014\end{array}$ & Qualitativo \\
\hline 5 & $\begin{array}{l}\text { Acesso, equidade e coesão social: avaliação } \\
\text { de estratégias intersetoriais para a população } \\
\text { em situação de } \text { rua }^{27}\end{array}$ & $\begin{array}{l}\text { Borysow IC, } \\
\text { Furtado JP }\end{array}$ & SP & $\begin{array}{l}\text { Rev Esc Enferm } \\
\text { USP / } 2014\end{array}$ & Qualitativo \\
\hline 6 & $\begin{array}{l}\text { Práticas de saúde das equipes dos } \\
\text { Consultórios de } \text { Rua }^{28}\end{array}$ & Silva FP et al. & $\mathrm{PE}$ & $\begin{array}{l}\text { Cad Saúde } \\
\text { Pública / } 2014 \\
\end{array}$ & Qualitativo \\
\hline 7 & $\begin{array}{l}\text { Consultório de/na rua: desafio para um } \\
\text { cuidado em verso na saúde }{ }^{29}\end{array}$ & Londero MFP et al. & $\mathrm{RS}$ & Interface / 2014 & Qualitativo \\
\hline 8 & $\begin{array}{l}\text { Acesso e intersetorialidade: o } \\
\text { acompanhamento de pessoas em situação de } \\
\text { rua com transtorno mental grave }{ }^{30}\end{array}$ & $\begin{array}{l}\text { Borysow IC, } \\
\text { Furtado JP }\end{array}$ & SP & Physis / 2013 & $\begin{array}{l}\text { Revisão } \\
\text { narrativa }\end{array}$ \\
\hline 9 & $\begin{array}{l}\text { Experiência POP RUA: Implementação do } \\
\text { "Saúde em Movimento nas Ruas" do Rio de } \\
\text { Janeiro, um Dispositivo Clínico/Político na } \\
\text { Rede de Saúde do Rio de Janeiro }\end{array}$ & Macerata IM & RJ & $\begin{array}{l}\text { Rev Polis e } \\
\text { Psique / } 2013\end{array}$ & $\begin{array}{l}\text { Relato de } \\
\text { experiência }\end{array}$ \\
\hline 10 & $\begin{array}{l}\text { A estratégia saúde da família para a } \\
\text { equidade de acesso dirigida à população } \\
\text { em situação de rua em grandes centros } \\
\text { urbanos }^{32}\end{array}$ & $\begin{array}{l}\text { Carneiro Junior } \mathrm{N} \\
\text { et al. }\end{array}$ & SP & $\begin{array}{l}\text { Saúde Soc / } \\
2010\end{array}$ & $\begin{array}{l}\text { Relato de } \\
\text { experiência }\end{array}$ \\
\hline 11 & $\begin{array}{l}\text { Atendimento à população de rua em um } \\
\text { centro de saúde escola na cidade de São } \\
\text { Paulo }^{33}\end{array}$ & Canônico RP et al. & SP & $\begin{array}{l}\text { Rev Esc Enferm } \\
\text { USP / } 2007\end{array}$ & $\begin{array}{l}\text { Relato de } \\
\text { Experiência }\end{array}$ \\
\hline 12 & $\begin{array}{l}\text { Rede social e promoção da saúde dos } \\
\text { "descartáveis urbanos" } 34\end{array}$ & Souza ES et al. & SP & $\begin{array}{l}\text { Rev Esc Enferm } \\
\text { USP / } 2007\end{array}$ & $\begin{array}{l}\text { Quanti- } \\
\text { qualitativo }\end{array}$ \\
\hline 13 & $\begin{array}{l}\text { O cuidado em situação de rua: revendo o } \\
\text { significado do processo saúde-doença }{ }^{35}\end{array}$ & Rosa AS et al. & SP & $\begin{array}{l}\text { Rev Bras } \\
\text { Enferm / } 2006\end{array}$ & Qualitativo \\
\hline 14 & $\begin{array}{l}\text { Os loucos de rua e as redes de saúde mental: } \\
\text { os desafios de cuidado no território e a } \\
\text { armadilha da institucionalização }^{36}\end{array}$ & Lisboa MS & SP & $\begin{array}{l}\text { TESE - PUC / } \\
2013\end{array}$ & Qualitativo \\
\hline
\end{tabular}


Quadro 2. Matriz de síntese das características dos estudos incluídos na revisão, de acordo com objetivos, metodologia e principais resultados - São Paulo, SP, Brasil, 2017.

\begin{tabular}{|c|c|c|c|}
\hline & Objetivo & Metodologia & Principais resultados \\
\hline 1 & $\begin{array}{l}\text { Caracterizar como } \\
\text { uma equipe de CR de } \\
\text { Manguinhos/RJ desenvolve } \\
\text { sua prática de cuidado à } \\
\text { saúde da população em } \\
\text { situação de rua }{ }^{23} \text {. }\end{array}$ & \begin{tabular}{|l|} 
Estudo de caso de abordagem \\
qualitativa. Observação \\
direta das ações de cuidado; \\
entrevistas semiestruturadas \\
com profissionais e \\
representantes de movimento \\
social; levantamento de dados.
\end{tabular} & $\begin{array}{l}\text { Todos os profissionais atendem na rua; ações } \\
\text { envolvem redução de danos. Há resistência } \\
\text { de outros profissionais em receber e atender } \\
\text { essa população: CR como sensibilizador e } \\
\text { articulador. Vínculo como eixo do cuidado. } \\
\text { Limitações: modo de funcionamento dos } \\
\text { serviços; limitação do acesso e da rede. }\end{array}$ \\
\hline 2 & $\begin{array}{l}\text { Investigar os modos de } \\
\text { atuação e as características } \\
\text { do trabalho de uma equipe } \\
\text { de CR junto a adultos } \\
\text { jovens em situação de rua, } \\
\text { usuários de substâncias } \\
\text { psicoativas }^{24} \text {. }\end{array}$ & $\begin{array}{l}\text { Estudo descritivo de } \\
\text { cunho exploratório com } \\
\text { metodologia qualitativa. } \\
\text { Entrevistas semiestruturadas } \\
\text { com profissionais da } \\
\text { equipe de CR de e usuários } \\
\text { acompanhados pela equipe. }\end{array}$ & $\begin{array}{l}\text { Ações enfocam demandas e necessidades } \\
\text { dos usuários. Atuação na rua é valorizada, } \\
\text { apesar de desafiadora. Enfoque nos direitos } \\
\text { humanos e construção de vínculos são } \\
\text { facilitadores. Sofrimento da equipe frente } \\
\text { a fragilidades dos usuários é dificultador. } \\
\text { Usuários avaliam positivamente o cuidado } \\
\text { recebido e reconhecem ganhos. }\end{array}$ \\
\hline 3 & $\begin{array}{l}\text { Refletir acerca do } \\
\text { cuidado destinado à } \\
\text { população em situação } \\
\text { de rua na perspectiva } \\
\text { socioantropológica }^{25} \text {. }\end{array}$ & $\begin{array}{l}\text { Observação participante de } \\
\text { uma equipe de Consultório } \\
\text { na Rua de Campinas. }\end{array}$ & $\begin{array}{l}\text { Há dificuldades em realizar ações devido } \\
\text { ao modo de funcionamento de serviços e } \\
\text { obstáculos na construção da rede. Oferta de } \\
\text { cuidados é restrita, diante das necessidades } \\
\text { observadas. Equipe pauta ações na } \\
\text { construção do vínculo, autonomia e respeito } \\
\text { e não apenas na intervenção clínica. }\end{array}$ \\
\hline 4 & $\begin{array}{l}\text { Descrever e analisar a } \\
\text { experiência no serviço } \\
\text { de CR na perspectiva dos } \\
\text { profissionais que compõem } \\
\text { a equipe de um município } \\
\text { da região metropolitana de } \\
\text { Recife }^{26} \text {. }\end{array}$ & $\begin{array}{l}\text { Estudo qualitativo } \\
\text { exploratório e descritivo. } \\
\text { Entrevista semiestruturada } \\
\text { com profissionais da equipe. }\end{array}$ & $\begin{array}{l}\text { Ações: orientar quanto a redução de } \\
\text { danos; ofertar e articular serviços. Bases } \\
\text { do cuidado: vínculo com usuário e seu } \\
\text { desejo. Realizadas reuniões para discussão } \\
\text { e planejamento Limitações: dificuldade de } \\
\text { acesso; falta de recursos e de investimentos } \\
\text { nos profissionais. }\end{array}$ \\
\hline 5 & $\begin{array}{l}\text { Compreender e avaliar } \\
\text { o trabalho da assistência } \\
\text { intersetorial dirigido a } \\
\text { pessoas em situação de rua, } \\
\text { com transtorno mental } \\
\text { grave, nos serviços públicos } \\
\text { de saúde mental }{ }^{27} \text {. }\end{array}$ & $\begin{array}{l}\text { Estudo de caso, composto de } \\
\text { observação participante em } \\
\text { albergue; entrevistas semi- } \\
\text { estruturadas com } 4 \text { usuários } \\
\text { acompanhados em CAPS } \\
\text { em uma cidade do interior } \\
\text { paulista; duas entrevistas não } \\
\text { diretivas em grupo ( } 5 \text { técnicos } \\
\text { da assistência social). } \\
\end{array}$ & $\begin{array}{l}\text { Há diferenças entre o programado e } \\
\text { o realizado. Faltam ações da saúde no } \\
\text { território e há divergência de ações entre } \\
\text { diferentes setores. Ações da assistência } \\
\text { social facilitam acesso e vinculação, mas há } \\
\text { dificuldades no compartilhamento devido a } \\
\text { restrições dos serviços e ausência de fluxos. }\end{array}$ \\
\hline 6 & $\begin{array}{l}\text { Conhecer as práticas de } \\
\text { saúde desenvolvidas pelas } \\
\text { equipes de Consultório na } \\
\text { Rua; descrever estratégias } \\
\text { de atuação; conhecer o } \\
\text { entendimento das equipes } \\
\text { sobre educação em saúde } \\
\text { e desvelar os sentimentos } \\
\text { sobre o processo de } \\
\text { trabalho na rua }{ }^{28} \text {. }\end{array}$ & $\begin{array}{l}\text { Estudo exploratório descritivo } \\
\text { realizado junto a duas equipes } \\
\text { de Consultório na Rua (uma } \\
\text { de Recife e outra de Olinda) } \\
\text { Composto de observação } \\
\text { participante e entrevistas } \\
\text { semi-estruturadas com } 15 \\
\text { trabalhadores. }\end{array}$ & $\begin{array}{l}\text { Mapeamento do território, abordagens } \\
\text { locais, visitas noturnas, planejamento e } \\
\text { trabalho em equipe contribuem para o } \\
\text { desenvolvimento de ações. } \\
\text { Vínculo, diálogo e escuta dos usuários são } \\
\text { vistos como imprescindíveis. Ações oriundas } \\
\text { das necessidades do campo e da demanda } \\
\text { de usuários. Barreiras advindas de outros } \\
\text { serviços limitam acesso. Equipe é um elo } \\
\text { entre a rua e a saúde. }\end{array}$ \\
\hline 7 & $\begin{array}{l}\text { Problematizar a estratégia } \\
\text { de acolhimento e cuidado } \\
\text { em saúde do Consultório } \\
\text { de/na Rua, suas diretrizes e } \\
\text { valores }^{29} \text {. }\end{array}$ & $\begin{array}{l}\text { Análise de diários de campo } \\
\text { escritos pelos trabalhadores } \\
\text { de uma equipe de Consultório } \\
\text { na Rua de Porto Alegre. }\end{array}$ & $\begin{array}{l}\text { Ações construídas a partir das } \\
\text { particularidades de cada sujeito: expressam } \\
\text { necessidades de saúde da população } \\
\text { para a rede. Serviços não disponíveis e } \\
\text { despreparados - risco de ações impositivas e } \\
\text { desarticuladas dos sujeitos. }\end{array}$ \\
\hline
\end{tabular}


Quadro 2. Matriz de síntese das características dos estudos incluídos na revisão, de acordo com objetivos, metodologia e principais resultados - São Paulo, SP, Brasil, 2017.

\begin{tabular}{|c|c|c|c|}
\hline & Objetivo & Metodologia & Principais resultados \\
\hline 8 & $\begin{array}{l}\text { Compreender o acesso } \\
\text { e a acessibilidade de } \\
\text { moradores de rua aos } \\
\text { serviços de saúde mental } \\
\text { a partir da intermediação } \\
\text { feita pelo setor de } \\
\text { assistência social }{ }^{30} \text {. }\end{array}$ & $\begin{array}{l}\text { Revisão narrativa de } \\
\text { literatura. Levantamento } \\
\text { bibliográfico na base de dados } \\
\text { Scielo e no banco de teses da } \\
\text { CAPES. }\end{array}$ & $\begin{array}{l}\text { Serviços de saúde mental enfrentam } \\
\text { dificuldades em atender na rua. O modo } \\
\text { como o serviço responde às peculiaridades } \\
\text { da população facilita ou dificulta acesso e } \\
\text { cuidado. Usuários chegam ao serviço por } \\
\text { intermédio da assistência social. }\end{array}$ \\
\hline 9 & $\begin{array}{l}\text { Expressar, apresentar } \\
\text { e discorrer acerca da } \\
\text { experiência do projeto } \\
\text { "Saúde em Movimento nas } \\
\text { Ruas", a partir da ótica do } \\
\text { gerente técnico da equipe }{ }^{31} \text {. }\end{array}$ & \begin{tabular}{|l} 
Descrição do processo de \\
montagem do serviço e \\
caracterização de suas ações e \\
de seu modo funcionamento.
\end{tabular} & $\begin{array}{l}\text { Agente comunitário de saúde como } \\
\text { peça chave do cuidado: vínculo e } \\
\text { longitudinalidade. Serviços com } \\
\text { funcionamento diferente do tempo da } \\
\text { população: CR como ponte, sensibilizador } \\
\text { e formador. Ações consideram demandas } \\
\text { singulares para redução de danos: promoção } \\
\text { de saúde como forma de produzir cidadania. }\end{array}$ \\
\hline 10 & $\begin{array}{l}\text { Relatar a experiência da } \\
\text { implantação da Estratégia } \\
\text { Saúde da Família (ESF) } \\
\text { para a atenção à saúde da } \\
\text { população em situação de } \\
\text { rua }^{32} \text {. }\end{array}$ & $\begin{array}{l}\text { Descrição do processo de } \\
\text { implantação das equipes de } \\
\text { ESF para a população em } \\
\text { situação de rua na cidade de } \\
\text { São Paulo: projeto "A gente } \\
\text { na rua". }\end{array}$ & $\begin{array}{l}\text { Equipes objetivam acompanhar pessoas } \\
\text { em seu local de moradia, vinculando-as à } \\
\text { UBS, e desenvolver ações básicas de saúde } \\
\text { por meio da assistência in loco e integração } \\
\text { com serviços e recursos locais. Iniciativa } \\
\text { favoreceu o acesso. }\end{array}$ \\
\hline 11 & $\begin{array}{l}\text { Relatar a experiência do } \\
\text { programa "A gente na rua" } \\
\text { em um Centro de Saúde } \\
\text { Escola }^{33} \text {. }\end{array}$ & $\begin{array}{l}\text { Descrição do funcionamento } \\
\text { de um Centro de Saúde Escola } \\
\text { e da Equipe "A gente na rua", } \\
\text { na cidade de São Paulo. }\end{array}$ & $\begin{array}{l}\text { Equipe realiza acolhimento e abordagem } \\
\text { das pessoas em situação de rua, na unidade } \\
\text { ou no território com foco em ações clínicas. } \\
\text { Atribui à resistência dos usuários a sua não } \\
\text { adesão à unidade. }\end{array}$ \\
\hline 12 & $\begin{array}{l}\text { Realizar o diagnóstico e } \\
\text { identificar os princípios } \\
\text { norteadores das } \\
\text { instituições públicas, } \\
\text { privadas e entidades sociais } \\
\text { que têm como público- } \\
\text { alvo pessoas adultas em } \\
\text { situação de rua }{ }^{34} \text {. }\end{array}$ & $\begin{array}{l}\text { Pesquisa-ação com aplicação } \\
\text { de questionário semi- } \\
\text { estruturado em } 19 \text { serviços } \\
\text { do centro da cidade de São } \\
\text { Paulo. Realizada oficina } \\
\text { participativa com } 5 \text { serviços, } \\
\text { que discutiu o conhecimento } \\
\text { acerca das instituições e o } \\
\text { relacionamento entre elas. }\end{array}$ & $\begin{array}{l}\text { Instituições costumam impor valores; } \\
\text { oferecem ações assistenciais, paliativas e } \\
\text { cronificantes. Prevalecem saberes técnicos, } \\
\text { indicando pouca articulação com a } \\
\text { população. Incoerência entre prática e } \\
\text { norteadores apontados (emancipação, } \\
\text { direitos, geração de renda, cidadania e rede } \\
\text { social). Setor saúde favorece articulação. }\end{array}$ \\
\hline 13 & $\begin{array}{l}\text { Conhecer o significado } \\
\text { do processo saúde- } \\
\text { doença-cuidado para } \\
\text { pessoas em situação de } \\
\text { rua e trabalhadores de um } \\
\text { centro comunitário de } \\
\text { atendimento à população } \\
\text { de rua }^{35} \text {. }\end{array}$ & $\begin{array}{l}\text { Pesquisa qualitativa, } \\
\text { exploratória. Entrevista semi- } \\
\text { estruturada realizada com } 4 \\
\text { adultos em situação de rua e } \\
4 \text { agentes comunitários que } \\
\text { trabalham em um centro } \\
\text { comunitário.na cidade de São } \\
\text { Paulo. }\end{array}$ & $\begin{array}{l}\text { Para os entrevistados, o processo saúde- } \\
\text { doença depende do indivíduo e o cuidado } \\
\text { é responsabilidade dos serviços de saúde. } \\
\text { Trabalhadores acreditam que o serviço é } \\
\text { de má qualidade devido ao despreparo dos } \\
\text { profissionais para lidar com essa população. }\end{array}$ \\
\hline 14 & $\begin{array}{l}\text { Investigar como se } \\
\text { configura a rede de atenção } \\
\text { e cuidado destinada às } \\
\text { pessoas em situação de } \\
\text { rua em sofrimento mental } \\
\text { e como se articulam as } \\
\text { intervenções em Saúde. } \\
\text { Acompanhar como são } \\
\text { acionadas redes de cuidado } \\
\text { e sobrevivência frente às } \\
\text { necessidades de saúde. } \\
\text { Compreender a potência } \\
\text { das relações de cuidado }{ }^{36} \text {. }\end{array}$ & $\begin{array}{l}\text { Estudo etnográfico: Uma } \\
\text { equipe do Programa de Saúde } \\
\text { da Família Sem Domicílio } \\
\text { de uma UBS do centro da } \\
\text { cidade de São Paulo foi } \\
\text { acompanhada durante um } \\
\text { ano. As observações foram } \\
\text { registradas em diário de } \\
\text { campo e a análise foi feita por } \\
\text { meio das narrativas coletadas. }\end{array}$ & $\begin{array}{l}\text { Equipe atua em consonância com o projeto } \\
\text { terapêutico singular e efetiva ações em } \\
\text { uma rede enfraquecida e com serviços } \\
\text { excludentes. A equipe consegue dar suporte } \\
\text { ao sofrimento e às necessidades em saúde } \\
\text { e se responsabiliza pelo cuidado integral } \\
\text { das pessoas. Ações focadas na autonomia, } \\
\text { vínculo e acolhimento. Aponta o risco } \\
\text { das ações serem atravessadas por práticas } \\
\text { de poder e dominação e resultarem em } \\
\text { institucionalização: risco de pessoas em } \\
\text { situação de rua com transtorno mental } \\
\text { serem internadas em hospitais psiquiátricos. }\end{array}$ \\
\hline
\end{tabular}




\section{Características das ações de saúde que buscam responder às necessidades da população em situação de rua}

Todos os estudos apresentam ações desenvolvidas junto às pessoas em situação de rua e problematizam necessidades dessa população. As principais ações descritas pelos estudos são: abordagens e atendimentos nas ruas e nos demais locais onde as pessoas se encontram ${ }^{23-26,28,31,32,36}$; construção de vínculo entre as pessoas, a equipe e os serviços de saúde $23-26,28,31,36$; desenvolvimento de ações básicas de saúde e de redução de da$\operatorname{nos}^{23-26,28,31,36}$; integração com serviços e recursos locais $^{23-26,28,31,36}$; mapeamento do território ${ }^{23,25,26,31}$; visitas noturnas ${ }^{26,28}$; enfoque à defesa dos direitos humamos e promoção da cidadania ${ }^{24,31}$ e intervenções de suporte ao sofrimento ${ }^{36}$.

Dez estudos ${ }^{23-26,28,29,31-33,36}$ descrevem e debatem experiências de equipes de saúde e $u^{27}$ descreve a experiência de trabalho intersetorial realizada por serviços da assistência social e um CAPS. Outros dois ${ }^{34,35}$ abordam a visão de serviços públicos e privados que oferecem ações às pessoas em situação de rua na cidade de São Paulo sobre o cuidado desenvolvido pela saúde e um último ${ }^{30}$ desenvolve uma revisão bibliográfica que problematiza o cuidado em saúde mental dirigido a essa população.

Dois estudos $^{27,30}$ descrevem dificuldades das pessoas em situação de rua em acessarem serviços de saúde e cuidarem de si, o que se agrava no caso de pessoas que apresentam transtorno mental. Defendem a importância da ação de profissionais que atuem como mediadores e realizem a aproximação entre as pessoas e os serviços. Recomendam que essas ações sejam realizadas por profissionais da assistência social e avaliam que os serviços de saúde realizam poucas ações na rua, tais como busca ativa e atendimentos extradomiciliares.

Os estudos que apresentam o trabalho desenvolvido pelas equipes de Consultório de/ na Rua ${ }^{23-26,28,29,36}$; pelo projeto "Saúde em Movimento nas Ruas", na cidade do Rio de Janeiro ${ }^{31}$ e pelo projeto "A Gente na Rua”, na cidade de São Paulo $^{32,33}$ - destacam a presença do setor saúde nas abordagens, no desenvolvimento de ações no território e no estabelecimento de vínculo entre equipes e usuários. Reconhecem a importância do desenvolvimento do cuidado longitudinal junto às pessoas acompanhadas e valorizam a realização de atendimentos na rua por parte de todos os profissionais das equipes.

Silva et al. ${ }^{28}$ descrevem abordagens realizadas por duas equipes de Consultório de Rua de Recife e Olinda que oferecem cuidados e redu- ção de danos no local onde as pessoas vivem. $\mathrm{O}$ mapeamento, o estudo do território e o contato prévio com a comunidade são apresentados como fatores que facilitam o desenvolvimento de ações, o que também foi observado em outros estudos $^{23,26,31}$. Visando à ampliação do acesso, as equipes também realizam ações noturnas, por compreenderem que essa população é itinerante e nem sempre se encontra nos mesmos locais de abordagem durante o dia ${ }^{28}$.

O estudo de Carneiro Júnior et al. ${ }^{32}$ apresenta a organização do projeto "A Gente na Rua”, desenvolvido em algumas UBS na cidade de São Paulo para prestação da assistência in loco e atuação de forma integrada com os diversos segmentos da comunidade. Avalia que as ações ampliaram o acesso desse grupo aos serviços da atenção básica.

Ao estudarem instituições que desenvolvem ações junto a pessoas em situação de rua no centro da cidade de São Paulo, Souza et al. ${ }^{34}$ identificam que o setor saúde influencia positivamente a articulação de ações em rede. Acreditam que isso resulta da assunção de diretrizes como universalidade, integralidade e equidade e da adoção da perspectiva de promoção de saúde.

Sete estudos ${ }^{23,24,26,28,29,31,36}$ observam a relevância do trabalho em equipe, realizado de modo multi e interdisciplinar. Essa forma de organização do trabalho possibilita a apreensão ampliada das necessidades da população; a oferta de cuidado integral ${ }^{28}$ e o rompimento com o modelo médico centrado ao integrar diferentes saberes e especificidades profissionais ${ }^{23,24}$, o que contribui para a construção de práticas coletivas e troca constante de saberes ${ }^{23}$; além de favorecer a partilha do gerenciamento de $\operatorname{casos}^{36}$. O trabalho em equipe permite também a adaptação de ações diante de eventualidades como falta de espaços e apoios que possam advir da abertura para as demandadas do território ${ }^{29}$. As reuniões de equipe são entendidas como espaços de educação permanente ${ }^{23} \mathrm{e}$ formação $0^{26,31}$, que favorecem discussão de casos; planejamento e ordenamento de ações ${ }^{26,28}$.

A função do Agente Comunitário de Saúde (ACS) é destacada por Carneiro Júnior et al. ${ }^{32}$; Macerata $^{31}$ e Lisboa ${ }^{36}$ e compreendida como potencializadora do trabalho em equipe por primar pela produção de vínculos e acolhimento de demandas, além de mesclar saberes, posições sociais e diferentes formações ${ }^{36}$. O fato dos ACS já terem familiaridade com o trabalho junto a essa população e/ou terem vivido em situação de rua amplia sua capacidade comunicacional e a compreensão da dinâmica dos territórios de abrangência das equipes, promovendo aproximações entre a instituição e a rua ${ }^{31}$. 
Londero et al. ${ }^{29}$ descrevem que a interação da equipe de Consultório de/na Rua com essa população, em seus diversos contextos, permite a apreensão de necessidades ampliadas de cuidado e a expressão dessas necessidades para a rede de serviços. Outros estudos ${ }^{23,31}$ também reconhecem o potencial sensibilizador do trabalho das equipes. Um deles ${ }^{23}$ destaca a importância dos profissionais mapearem e tecerem relações com os serviços da rede, de modo a assegurar o cuidado integral às pessoas em situação de rua; e o outro $^{31}$ identifica que o compartilhamento de ações com outros serviços, bem como o matriciamento, promovem a atenção integrada, contribuem para a formação das equipes e consequentemente aprimoram o cuidado.

Lisboa $^{36}$ e Macerata ${ }^{31}$ destacam que as equipes estudadas se mantêm atentas às situações de vulnerabilidade; atuam em consonância com as necessidades de saúde observadas e conseguem dar suporte ao sofrimento dos usuários, mesclando saberes da Atenção Básica e da Saúde Mental nas ações ofertadas. Porém Lisboa ${ }^{36}$ ressalta que é preciso abrir caminhos para que seja possível efetivar ações complexas. Silva et al..$^{23}$ compreendem que o trabalho do Consultório na Rua permitiu muitos avanços; porém a ampliação do acesso ainda não se encontra plenamente garantida.

\section{Fatores que limitam as ações e restringem a resposta às necessidades da população em situação de rua}

De um modo geral, os estudos avaliam que as equipes voltadas ao cuidado à população em situação de rua muitas vezes encontram limitações para executar ações devido a dificuldades dos demais serviços de saúde em oferecer atendimento a essa população e compartilhar o cuidado.

A situação desse grupo, que em sua maioria encontra dificuldades em manter o autocuidado e em decorrência se apresenta com falta de higiene, associada aos efeitos do uso de álcool e/ ou drogas, provocam o afastamento dos profissionais, produzem restrições nos acolhimentos e por vezes impedem atendimentos ${ }^{23,25,26,27,30}$. Requisições burocráticas, como a exigência de documentos e comprovante de residência, além de limitações no agendamento de consultas e inflexibilidade de horários, reforçam o processo de exclusão vivenciado ${ }^{25,26}$.

A exigência da presença de familiares e/ou de pessoas responsáveis, feita por hospitais ou pronto socorros, muitas vezes impede que as pessoas em situação de rua sejam atendidas ou internadas $^{25,30}$. Tais obstáculos colocados pelos serviços representam uma forma de exclusão, que burocratiza a prática e reforça o preconceito ao qual essa população se encontra exposta ${ }^{28,36}$.

Lisboa $^{36}$ descreve que a rede de serviços estudada se apresenta fracamente estabelecida e não se responsabiliza pelo cuidado a esse grupo. Borysow e Furtado ${ }^{27}$ também destacam que a articulação entre os serviços da rede é difícil e que muitas vezes os fluxos não são instituídos e se efetivam apenas por meio de contatos pessoais.

Souza et al. ${ }^{26}$ identificam que a ausência de uma rede consolidada de atendimento noturno também é um fator prejudicial à estruturação do cuidado e desenvolvimento de ações, bem como o número insuficiente de recursos físicos e materiais; profissionais; equipes e serviços ${ }^{23}$.

Outros dois aspectos apresentados como obstáculos à realização de boas práticas são a discrepância de atuação e a desarticulação entre diferentes serviços e/ou setores. Enquanto alguns serviços baseiam suas ações no respeito à população e na promoção de sua autonomia, outros atuam de forma autoritária, impositiva e higienista ${ }^{23-25,27,36}$. Por serem vítimas de repreensões, encaminhamentos indiscriminados e/ou ações de recolhimentos por parte de serviços de outras Secretarias de Estado, muitas vezes essa população se apresenta insegura em buscar os serviços de saúde ${ }^{23}$.

Londero et al..$^{29}$, bem como Lima e Seidl ${ }^{24}$, avaliam que o trabalho junto a essa população provoca angústia e sofrimento nos profissionais pelo contato com situações de desamparo e de invalidação dos direitos dos usuários, além de demandar intenso investimento afetivo. Tais condições são difíceis de serem manejadas e podem produzir ações desarticuladas dos sujeitos, prescritivas, resolutivas e impositivas ${ }^{29}$.

Lisboa $^{36}$, apesar de reconhecer a consonância do trabalho realizado com as proposições da Política Pública e com o cuidado integral, reconhece que há o risco das ações serem atravessadas por práticas de poder e dominação que podem se desdobrar em intervenções de controle e regulação e culminar na institucionalização dos usuários.

Alguns estudos ${ }^{27,34}$ descrevem dissonâncias entre o que os serviços se propõem a fazer e o que de fato realizam. Souza et al..$^{34}$ identificam que instituições dirigidas a essa população apresentam em seus objetivos termos como "emancipação, direitos, geração de renda, cidadania e rede social", porém desenvolvem práticas assistencialistas e costumam impor seus próprios valores em resposta à visão de que as pessoas em situação de rua são desprovidas "de tudo, inclusive de história, vontades, valores e costumes". Os autores ainda observam que o saber técnico e a 
imposição de valores prevalecem, o que sugere pouca escuta e articulação com as pessoas em situação de rua e seus representantes.

O estudo de Canônico et al. ${ }^{33}$ descreve a experiência de uma das equipes do projeto "A Gente na Rua" em um Centro de Saúde Escola da cidade de São Paulo e apresenta algumas estratégias desenvolvidas por essa equipe para a continuidade do cuidado a essa população e sua vinculação ao serviço. Porém, no trecho abaixo, o usuário é culpabilizado por sua não adesão:

(...) frequentemente é necessário lembrar ao morador de rua sobre as condutas tomadas e reforçar que o tratamento e continuação do acompanhamento dependem mais dele do que do próprio serviço (...) há ainda muita resistência por parte dessa população em aderir à unidade de saúde enquanto usuário do SUS e reconhecer que é preciso cuidar da saúde (...).

Os achados do estudo de Rosa et al. ${ }^{35}$ mostram que os trabalhadores de um centro comunitário voltado para essa população consideram que "cabe ao indivíduo em situação de rua saber se cuidar" e que "o processo saúde-doença depende do indivíduo e o cuidado é responsabilidade dos serviços de saúde". Na opinião desses trabalhadores, os serviços de saúde são de má qualidade devido ao despreparo de profissionais para lidar com esse grupo, ao estigma e à discriminação na prestação de cuidados. Os autores percebem a necessidade de educação permanente, formações e capacitações aos profissionais sobre as especificidades dessa população, o que também é percebido em outros estudos $23,26,29,30,34$.

Hallais e Barros ${ }^{25}$ constatam que a oferta de cuidados do Sistema Único de Saúde (SUS) é limitada, diante das condições de precariedade, privação e invisibilidade vivenciadas por essa população, e ressaltam que as Políticas Públicas atuais não garantem o cuidado integral. Lisboa ${ }^{36}$ destaca a necessidade de se construir uma linha de cuidado para esse grupo que seja pautada nas suas características e leve em conta determinantes do processo saúde-doença e seus principais problemas clínicos, além das dificuldades enfrentadas no relacionamento com a rede de cuidados.

\section{Participação das pessoas em situação de rua no planejamento e na execução das ações oferecidas pelos serviços de saúde}

Alguns estudos consideram a importância da prática ser pautada na relação entre o serviço e o usuário. Cinco deles ${ }^{23-26,31}$ destacam que as ações desenvolvidas pelas equipes estudadas são norteadas pelo estabelecimento de vínculo en- tre profissionais e pessoas atendidas e levam em conta a escuta qualificada, o olhar humanizado, o respeito às escolhas e autonomia de cada sujeito e a redução de danos como conduta. $\mathrm{O}$ trabalho se constitui como um cuidado emancipador, que tem como enfoque a promoção dos direitos dos usuários, e se constrói a partir do encontro, com o objetivo de dar visibilidade às pessoas ao invés de focar somente na melhora clínica. Os usuários são vistos pelos profissionais como sujeitos e não como objetos de intervenção, e constata-se que a construção de relações de confiança, a partir do estabelecimento do vínculo, facilita aproximação e desenvolvimento do cuidado.

Silva et al. ${ }^{23}$ descrevem que a chegada de novos usuários leva a equipe a repensar suas estratégias e reestruturar ações, de modo a encontrar formas de vinculação possíveis e se adequar à realidade de vida de cada um deles. Para Macerata $^{31}$, a possibilidade da equipe trabalhar individualmente as demandas de cada usuário está interconectada à lógica da redução de danos, cujo enfoque é a construção de estratégias singulares que ampliem o grau de saúde de cada sujeito e/ ou comunidade. A redução de danos é compreendida, portanto, como uma forma de se relacionar com o usuário, e não se qualifica somente pela oferta de insumos.

Silva et al. ${ }^{28}$ destacam a relevância da relação dialógica e da escuta e enunciam que a criação de vínculo exige dos profissionais criatividade e envolvimento afetivo, aspecto também reconhecido em outros estudos ${ }^{23,26}$. Sobre a especificidade do trabalho realizado, descrevem que as práticas territoriais se dão a partir do reconhecimento das necessidades dos usuários atendidos e que a equipe se constitui como um elo entre as situações vividas na rua e os serviços de saúde, o que também é afirmado por Macerata ${ }^{31}$. São realizadas oficinas no território, de acordo com interesses e possibilidades, que incentivam participação e vinculação, estratégia semelhante à descrita por Souza et al. $^{26}$. As ações apresentadas não se configuram como assistencialistas, pois são pautadas nas demandas dos usuários. A possibilidade dos profissionais colocarem as necessidades e desejos das pessoas atendidas em primeiro lugar evita frustrações por parte da equipe.

Londero et al. ${ }^{29}$ identificam a necessidade dos profissionais instituirem pausas reflexivas no decorrer do trabalho, de modo a possibilitar a articulação entre os saberes e as necessidades e desejos dos usuários na composição das estratégias de cuidado.

No trabalho desenvolvido pela equipe estudada por Lisboa ${ }^{36}$, a demanda das ações parte do 
usuário e do que ele identifica como prioridade. Observa-se o comprometimento com as necessidades identificadas e o enfoque na construção do vínculo e no incentivo à autonomia. No estudo de Lima e Seidl ${ }^{24}$, usuários avaliam que as ações oferecidas pela equipe melhoram sua condição de saúde, reduzem riscos e são fontes de carinho e cuidado. A preocupação e a dedicação da equipe são reconhecidas pelos usuários, que valorizam a perseverança e o envolvimento dos profissionais com o trabalho.

Nas experiências de trabalho citadas ${ }^{23-26,28,29,31,36}$ a construção do vínculo é descrita como essencial para o desenvolvimento das ações. A participação do usuário nesse processo também é compreendida como importante por contribuir com práticas pautadas na ética, que levam em conta o desejo do sujeito, suas necessidades e prioridades.

\section{Discussão}

Por meio desta revisão integrativa, na qual 13 artigos e uma tese de doutorado foram analisados, buscou-se identificar se as ações de saúde descritas na literatura respondem às necessidades das pessoas em situação de rua e se levam em conta as prioridades e opiniões apontadas por elas.

As equipes de Consultório na Rua e os CAPS são componentes da RAPS e os estudos mostram que esses serviços realizam parcialmente o que é preconizado pelas diretrizes. Apesar dos obstáculos descritos, investem na garantia de acesso e na construção de vínculo; inclusão social; humanização; redução de danos e construção de PTS em rede $^{14,15}$.

Nove estudos descrevem a experiência de equipes ${ }^{23-26,28,29,31,36}$ ou apresentam propostas de atuação de equipes ${ }^{32}$ que se mostram comprometidas com o trabalho desenvolvido e que parecem ancorar as ações em conceitos como vínculo, escuta, responsabilização, clínica ampliada, cuidado integral, intersetorialidade, respeito aos direitos humanos e garantia de autonomia e liberdade $^{15}$. A atenção básica se apresenta como articuladora da rede, conforme preconizado, e há indícios de reflexões, trocas e cruzamento de saberes entre as profissões nos locais de trabalho ${ }^{14}$.

Apesar dos investimentos positivos e articulações com as diretrizes das RAPS, são encontrados obstáculos nesse processo. Algumas equipes $^{23-26,27,28,30,34,36}$ relatam dificuldades em articular o trabalho em rede de modo a responder a urgências e realizar ações complexas, o que sugere insuficiência na integração dos pontos da rede de cuidado e ausência de corresponsabilização ${ }^{14}$.
O modo de funcionamento de alguns serviços, ao limitar o acesso de usuários devido a preconceitos, burocratizações e não flexibilizações de práticas diante de necessidades apresentadas pelas pessoas em situação de rua ${ }^{23,25,26,28,30,34,36}$, pode se apresentar como uma barreira à efetivação do trabalho em rede, juntamente com a ausência de fluxos entre os serviços ${ }^{27}$ e de linhas de cuidado para essa população ${ }^{36}$.

Aspectos como o risco de imposição de saberes técnicos em detrimento à escuta qualificada dos usuários e de execução de ações resolutivas e assistenciais, advindos dos sentimentos de desamparo e angústia provocados pelo contato com a vulnerabilidade à qual a população de rua se encontra submetida ${ }^{29,36}$, compõem uma possível fonte de sobrecarga aos profissionais e assinalam a necessidade de educação permanente ${ }^{14,15}$ identificada em alguns estudos ${ }^{26,28,29,34,36}$.

Os estudos evidenciam importantes contribuições das equipes de saúde aos cuidados da população em situação de rua. A presença cotidiana de profissionais junto a essas pessoas favorece o reconhecimento de suas necessidades e a construção de relações de confiança.

A vinculação ao usuário, sua escuta e o seu envolvimento no cuidado são fatores que contribuem para a realização do trabalho. Observam-se esforços em responder às necessidades identificadas e alinhar as ações às normativas que regem os serviços públicos de saúde, porém são muitos os desafios encontrados nesse processo.

Há a necessidade de se refletir sobre os impactos produzidos por este trabalho no cotidiano dos profissionais e sobre maneiras de ampliar o acesso e expandir ações de cuidado, de modo a implicar serviços, gestores e Políticas nesse processo.

Um aspecto que chama a atenção nessa revisão é o reduzido número de estudos encontrados. Em sua maioria, são estudos pequenos, que descrevem experiências relevantes junto à população em situação de rua. Os dados levantados confirmam que as equipes de Consultório na Rua, componentes da Atenção Básica da RAPS, ofertam ações pautadas no acolhimento, escuta qualificada e atenção às vulnerabilidades e necessidades da população em situação de rua. Porém, é possível perceber que, até o momento, são poucas as publicações que estudam especificamente o cuidado a esse grupo oferecido pelos serviços de saúde mental especializados, como os Centros de Atenção Psicossocial (CAPS), e pelos serviços de urgência e emergência, também componentes da RAPS.

Pelo fato deste estudo buscar conhecer características das ações dirigidas à população em situação de rua, de modo a identificar se elas são 
construídas a partir do diálogo entre serviços e pessoas atendidas e se respondem às suas necessidades, não foram enfocados artigos que discutem os principais problemas de saúde dessa população e não foram descritas as ações que buscam respondê-los. Há a necessidade de estudos mais específicos que debatam tais aspectos, de modo a contribuir com a prática de equipes que vivenciam desafios cotidianos para a oferta do cuidado integral a essa população.

Acredita-se que esta é uma área que demanda maiores pesquisas e investigações, inclusive estudos observacionais e mais abrangentes em termos populacionais, de modo a produzir evidências mais consistentes, bem como referenciais e novas reflexões para a prática de equipes de saúde.

\section{Considerações finais}

Este estudo de revisão possibilitou o aprofundamento da reflexão sobre a relevância e o papel do cuidado à população em situação de rua oferecido pelos serviços de saúde, no contexto da RAPS, e contribuiu para a construção de um panorama inicial e exploratório sobre o estado da arte de estudos nesse campo. Observa-se que apesar da relevância social da temática são poucos os estudos que se debruçam sobre ela. De um modo geral são estudos qualitativos, exploratórios e de pequena abrangência na medida em que focam em experiências locais de poucas equipes e serviços.

Apesar das limitações encontradas na literatura, os aspectos levantados pelos estudos trazem contribuições fundamentais que apoiam as iniciativas de ampliação e fortalecimento da oferta de atenção intersetorial à população em situação de rua, em especial às pessoas que apresentam transtorno mental.

Apoiam também a necessidade de fortalecer o paradigma e a construção das redes de serviço e a manutenção de Políticas Públicas destinadas especificamente a essa população, pois tornam claro que os investimentos desenvolvidos, apesar de limitados e por vezes contraditórios em relação ao preconizado pelas diretrizes da RAPS, sustentam avanços no acesso a recursos públicos e em especial à garantia de direitos básicos para a manutenção da vida.

\section{Colaboradores}

LB van Wijk realizou a revisão e redigiu o artigo. EF Mângia colaborou na concepção, redação e revisão do artigo.

\section{Referências}

1. Brasil. Governo Federal. Política Nacional para Inclusão Social da População em Situação de Rua. Brasília: Ministério do Desenvolvimento Social e Combate à Fome (MDS); 2008.

2. Aguiar MM, Iriart JAB. Significados e práticas de saúde e doença entre a população em situação de rua em Salvador, Bahia, Brasil. Cad Saude Publica 2012; 28(1):115-124.

3. Valencia E, Saez H, Kool J, Santos JFC, Cavalcanti MT, Lovisi GM. Homelessness and mental health in New York City: an overview 1994-2006. Cad Saúde Coletiva 2011; 19(1):20-26.

4. Barata RB, Carneiro Junior N, Ribeiro MCSA, Silveira C. Desigualdade social em saúde na população em situação de rua na cidade de São Paulo. Saúde Soc 2015; 24(1):219-232.

5. Botti NCL, Castro CG, Silva AK, Silva MF, Oliveira LC, Castro ACHOA, Fonseca LLK. Avaliação da ocorrência de transtornos mentais comuns entre a população de rua de Belo Horizonte. Barbarói 2010; (33):178-193.

6. Sarradon-Eck A, Farnarier C, Hymans TD. Caring on the margins of the healthcare system. Anthropology of Medicine 2014; 21(2):251-263. 
7. Skosireva A, O'Campo P, Zerger S, Chambers C, Gapka S, Stergiopoulos V. Different faces of discrimination: perceived discrimination among homeless adults with mental illness in healthcare settings. BMC Health Care Research 2014; 14:376.

8. Chrystal J, Glover D, Young AS, Whelan F, Austin EL, Johnson NK, Pollio DE, Holt CL, Stringfellow E, Gordon AJ, Kim TA, Daigle SG, Stewart JL, Kertesz SG. Experience of primary care among homeless individuals with mental health conditions. PLOS ONE 2015; 10(2): 0117395.

9. World Health Organization (WHO). Regional Office for Europe's Health Evidence Network (HEN). How can health care systems effectively deal with the major health care needs of homeless people? Geneva: WHO; 2005.

10. Meta Instituto de Pesquisa e Opinião, Secretaria de Avaliação e Gestão de Informação, Ministério do Desenvolvimento Social e Combate à Fome (MDS). Sumário executivo. Pesquisa nacional sobre a população em situação de rua. Brasília: MDS; 2008.

11. Natalino MAC. Estimativa da população em situação de rua no Brasil. Brasília: Instituto de Pesquisa Econômica e Aplicada; 2016

12. Organização Mundial de Saúde (OMS). Relatório sobre a Saúde no Mundo. Saúde Mental: Nova Concepção, Nova Esperança. Geneva: OMS; 2001.

13. Brasil. Ministério da Saúde (MS). Conselho Nacional de Saúde (CNS). Comissão Organizadora da IV Conferência Nacional de Saúde Mental - Intersetorial. Relatório final da IV Conferência Nacional de Saúde Mental Intersetorial. Brasília: CNS; 2011.

14. Brasil. Ministério da Saúde (MS). Portaria No 4.279, de 30 de dezembro de 2010. Estabelece diretrizes para a organização da Rede de Atenção à Saúde no âmbito do Sistema Único de Saúde. Diário Oficial da União 2010; $31 \mathrm{dez}$.

15. Brasil. Ministério da Saúde (MS). Portaria No 3.088, de 23 de dezembro de 2011. Institui a Rede de Atenção Psicossocial para pessoas com sofrimento ou transtorno mental e com necessidades decorrentes do uso de crack, álcool e outras drogas, no âmbito do Sistema Único de Saúde. Diário Oficial da União 2011; 26 dez.

16. Brasil. Ministério da Saúde (MS). Portaria ${ }^{\circ} 122$, de 25 de janeiro de 2012. Define as diretrizes e funcionamento das equipes de consultório na rua. Brasília. Diário Oficial da União 2012; 26 jan.

17. Brasil. Ministério da Saúde (MS). Secretaria de Atenção à saúde. Departamento de Atenção Básica. Departamento de Ações Programáticas Estratégicas. Coordenação de Área Técnica de Saúde Mental. Nota Técnica Conjunta/2012. Brasília; 2012.

18. Trino AT, Machado MPM, Rodrigues RB. Conceitos norteadores do cuidado junto à população em situação de rua. In: Teixeira M, Fonseca Z, organizadores. Saberes e práticas na Atenção Primária à Saúde - cuidado à população em situação de rua e a usuários de álcool, crack e outras drogas. São Paulo: Editora Hucitec; 2015, pg 27-44.

19. Brasil. Portal da Saúde. Estratégias e Ações de Saúde voltadas para População em Situação de Rua. [acessado 2016 Jun 14]. Disponível em: http://portalsaude.saude.gov. br/index.php?option $=$ com_content\&view $=$ article\&i$\mathrm{d}=18974 \&$ Itemid $=1005 \#$ estrategias/
20. Brasil. Ministério da Saúde (MS). Manual sobre o cuidado à saúde junto à população em situação de rua. Brasília: MS; 2012.

21. Soares CB, Hoga LAK, Peduzzi M, Sangaleti C, Yonekura T, Silva DRAD. Revisão integrativa: conceitos e métodos utilizados na enfermagem. Rev Esc Enferm USP 2014; 48(2):335-345.

22. Botelho LLR, Cunha CCA, Macedo M. O método da revisão integrativa nos estudos organizacionais. Gest Soc 2011; 5(11):121-136.

23. Silva CC, Cruz MM, Vargas EP. Práticas de cuidado e população em situação de rua: o caso do Consultório na Rua. Saúde Debate 2015; 39(Esp.):245-256.

24. Lima HS, Seidl EMF. Consultório na Rua: atenção a pessoas em uso de substâncias psicoativas. Psicologia em estudo 2015; 20(1):57-69.

25. Hallais JS, Barros NF. Consultório na Rua: visibilidades, invisibilidades e hipervisibilidade. Cad Saude Publica 2015; 31(7):1497-1504.

26. Souza VCA, Pereira AR, Gontijo DT. A experiência no serviço de Consultório de Rua na perspectiva dos profissionais: contribuiçãoes para a atenção ao usuário de álcool e outras drogas. Cad Ter Ocup UFSCar 2014; 22(Especial):37-47.

27. Borysow IC, Furtado JP. Acesso, equidade e coesão social: avaliação de estratégias intersetoriais para a população em situação de rua. Rev Esc Enferm USP 2014; 48(6):1069-1076.

28. Silva FP, Frazão IS, Linhares FMP. Práticas de saúde das equipes dos Consultórios de Rua. Cad Saude Publica 2014; 30(4):805-814.

29. Londero MFP, Ceccim RB, Bilibio LFS. Consultório de/na rua: desafio para um cuidado em verso na saúde. Interface (Botucatu) 2014; 18(49):251-260.

30. Borysow IC, Furtado JP. Acesso e intersetorialidade: o acompanhamento de pessoas em situação de rua com transtorno mental grave. Physis 2013; 23(1):33-50.

31. Macerata IM. Experiência POP RUA: implementação do "Saúde em Movimento nas Ruas" do Rio de Janeiro, um dispositivo clínico/político na Rede de Saúde do Rio de Janeiro. Rev Polis e Psique 2013; 3(2):207-219.

32. Carneiro Júnior N, Jesus $\mathrm{CH}$, Crevelim MA. A estratégia Saúde da Família para a equidade de acesso dirigida à população em situação de rua em grandes centros urbanos. Saúde Soc 2010; 19(3):709-716.

33. Canônico RP, Tanaka ACD, Mazza MMPR, Souza MF, Bernat $\mathrm{MC}$, Junqueira LX. Atendimento à população de rua em um Centro de Saúde Escola na cidade de São Paulo. Rev Esc Enferm USP 2007; 41(Esp):799-803.

34. Souza ES, Silva SRV, Caricari AM. Rede social e promoção da saúde dos "descartáveis urbanos". Rev Esc Enferm USP 2007; 41(Esp):810-814.

35. Rosa AS, Secco MG, Brêtas ACP. O cuidado em situação de rua: revendo o significado do processo saúdedoença. Rev Bras Enferm 2006; 59(3):331-336.

36. Lisboa MS. Os loucos de rua e as redes de saúde mental: os desafios do cuidado no território e a armadilha da institucionalização [tese]. São Paulo: Pontifícia Universidade Católica de São Paulo; 2013.

Artigo apresentado em 08/02/2017

Aprovado em 13/02/2018

Versão final apresentada em 15/02/2018 